\title{
基于时差法三维定位系统对闪电放电过程的观测 研究
}

张广庶 ${ }^{(1 *}$, 王彦辉 ${ }^{(1)}$, 郄秀书 ${ }^{(2)}$, 张粀 ${ }^{(1)}$, 赵玉祥 ${ }^{(1)}$, 李亚珺 ${ }^{(1)}$, 曹冬杰 ${ }^{(1)}$

(1) 中国科学院寒区早区环境与工程研究所西部气候环境与灾害实验室, 兰州 730000;

(2) 中国科学院大气物理研究所中层大气与全球环境探测实验室, 北京 100029;

(3) 天水师范学院物理系, 天水 741001

*E-mail: zhanggs@lzb.ac.cn

收稿日期: 2009-04-30; 接受日期: 2009-11-22

国家自然科学基金(批准号：40775004)、中国科学院知识创新工程重要方向项目(编号：KZCX2-YW-206-2)和公益性行业科研专项(编号： GYHY $(Q X) 2007622)$ 资助

\begin{abstract}
摘要系统介绍了自行研制的基于 GPS 同步和时差法定位技术的闪电 VHF 辐射源三维 定位系统以及山东北部地区闪电过程同步观测分析，成功获得了雷暴中闪电通道辐射源 三维时空发展物理图像. 并结合地面的快电场变化资料, 对典型负地闪、正地闪和云闪放 电通道的三维时空演变过程进行了分析，结果表明，正、负地闪激发传输过程不同，典型 负地闪的预击穿过程发展速度约为 $5.2 \times 10^{4} \mathrm{~m} / \mathrm{s}$, 被初始负击穿引发的向下梯级先导传输 过程发展速度约为 $1.3 \times 10^{5} \mathrm{~m} / \mathrm{s}$; 正地闪初始阶段也是激发负流光传输, 以优势水平方向在 正电荷区内传输, 并为始发点积累正电荷, 从而触发向下正流光传输. 重点分析了一次由 双极性窄脉冲事件(NBP)引发的云内闪电三维放电过程, 该脉冲发生在约 $10.5 \mathrm{~km}$ 的高度 上即上部正电荷区域内, 同时引发云内放电通道水平向周围扩展, 产生大量击穿辐射源, 双极性窄脉冲辐射峰值强度值高达 $16.7 \mathrm{~kW}$, 而普通闪电辐射源功率一般在 $100 \mathrm{~mW}$ $500 \mathrm{~W}$ 范围内. 与经典云闪完全不同, 此类新型云闪及其三维传输过程在国内第一次被发 现. 文章还讨论了其可能的触发机制.

关键词

时差法

闪电三维定位系统

放电过程

双极性窄脉冲

新型云闪
\end{abstract}

实现闪电辐射源三维高分辨率时空定位是精细 研究闪电放电过程、雷暴电荷结构及其形成机理的新 型手段. 闪电区分为地闪和云闪, 由于地闪常常引起 严重灾害, 人们对地闪关注较多, 地闪定位系统和 VHF干涉仪定位系统(二维)的应用, 在闪电定位技术 以及地闪机理研究方面取得了很多有意义的结果 ${ }^{[1 ~ 3]}$, 近年来雷电探测技术已向精细化方向进展, 在
$\operatorname{LDAR}^{[4]}$ 基础上，美国(New Mexico Institute of Mining and Technology)科学家发展了基于GPS系统的闪电 VHF辐射源到达时间差(TOA)定位系统(LMA), 研究 了闪电 VHF辐射源的三维时空演变过程 ${ }^{[5 \sim 7]}$, 张义 军等 ${ }^{[8 \sim 11]}$ 也利用该LMA系统的资料, 揭示了雷暴正 常三极性电荷结构特点并指出, 云内放电不仅发生 于上部正电荷区与中部主负电荷区之间, 还存在着

引用格式: Zhang G S, Wang Y H, Qie X S, et al. Using lightning locating system based on time-of-arrival technique to study three-dimensional lightning discharge processes. Sci China Earth Sci, 2010, 53: 591 - 602, doi: 10.1007/s11430-009-0116-x 
反极性放电过程. 祝保友和陶善昌等 ${ }^{[12]}$ 利用自行研 制的观测系统对雷暴云中产生的双极性窄脉冲事件 进行了统计分析. Shao 等 ${ }^{[13]}$ 和郄秀书等 ${ }^{[14]}$ 利用闪电 在低频频段的TOA组网观测对雷电放电特征进行了 研究. 但迄今为止, 国内尚缺乏类似于LMA的定位 系统. 从而无法对雷暴电荷结构及形成机理做更精 细的研究. 本文介绍了我们自行研制的具有高时空 分辨率的闪电 VHF辐射源三维定位系统, 以及观测 分析了我国雷暴的地闪和云闪放电的三维时空演变 过程的全景图像, 并对其发展特征和闪电强放电的 VHF辐射峰值强度进行了详细讨论, 初步揭示了闪 电放电通道及云中电荷区分布的三维时空结构, 正、 负地闪的不同放电机理, 尤其是讨论了具有起始双 极性窄脉冲云闪的结构和可能机理.

\section{1 野外实验场地及观测仪器}

2007 年 6 8 月期间在山东滨州地区进行了雷电 综合观测实验, 以中心站(沾化横店)为原点, 在其辐 射方向均匀分布建立了 6 个观测子站, 中心站西北方 向 $550 \mathrm{~m}$ 处建有人工引发雷电实验场(图 1). 实验区 域东靠渤海湾(约 $50 \mathrm{~km}$ ), 海拔高度 5 10 m, 半径 80 $\mathrm{km}$ 区域内地势比较平坦. 实验区处于南北天气系统 的交汇处, 夏季常有十分强烈的雷暴系统过境. 每个 测站安装有用于闪电辐射脉冲三维定位的闪电 VHF

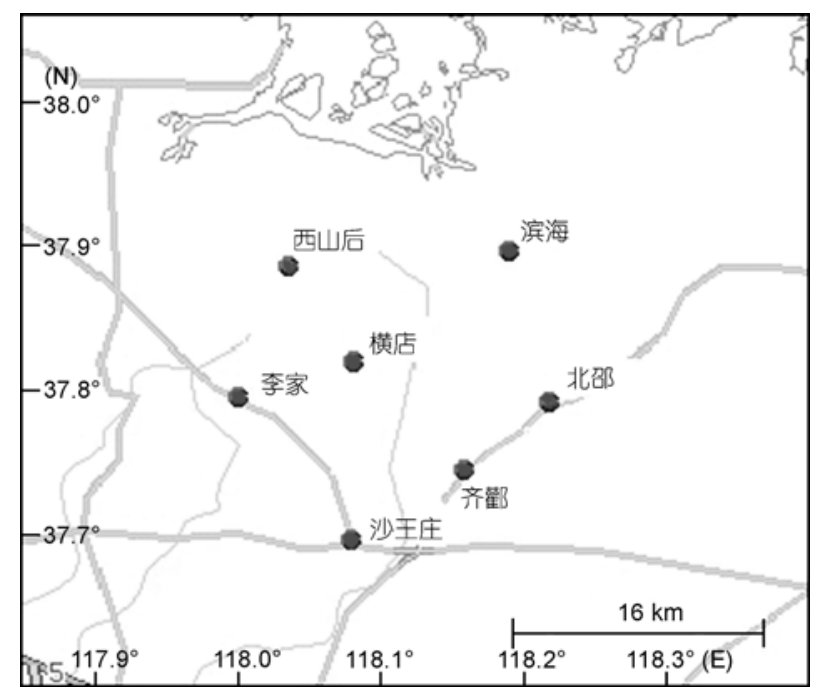

图 1 测站分布示意图

中心站横店和相应的 6 个子站
辐射源到达时间差(TOA)定位系统(简称 LLR)和 GPS 同步的高精度时钟 $( \pm 25 \mathrm{~ns})$, 以及用于闪电快电场变 化测量的宽带电场变化测量仪(带宽0 10 MHz, 时间 常数 $100 \mu \mathrm{s}$, 动态范围 $\pm 3.5 \mathrm{~V}$ )、快电场测量仪(带宽 $0 \sim 5 \mathrm{MHz}$, 时间常数 $1 \mathrm{~ms}$, 动态范围 $\pm 10 \mathrm{~V}$ )、慢电场 测量仪(带宽 $0 \sim 2 \mathrm{MHz}$, 时间常数 $6 \mathrm{~s}$, 动态范围 $\pm 10 \mathrm{~V}$ ) 和大气平均电场仪 $( \pm 50 \mathrm{kV} / \mathrm{m})$, 这些仪器获得模拟信 号并通过数字化 $\mathrm{A} / \mathrm{D}$ 板卡转换后送入 $\mathrm{PC}$ 微机同步记 录. 中心站另安装有高速摄像仪(100000 幅/s)、云顶 向上放电拍摄装置、闪电 VHF 窄带干涉仪系统等. 7 个 LLR 用无线宽带接入系统连接组成无线同步测量 网络, 数据采集可由中心站控制或自动运行. 本文分 析以电场负向变化时对应头顶正电荷减少的假定.

\section{2 辐射源三维时空定位原理}

\section{1 系统硬件实现原理}

闪电 VHF 辐射源三维定位系统由 7 个探测子站 组成, 如图 1 所示. 每个站同步接收闪电放电时产生 的 VHF 电磁辐射的脉冲峰值信号, 如图 2 所示. 接收 机的中心频率 $270 \mathrm{MHz}, 3 \mathrm{~dB}$ 带宽 $6 \mathrm{MHz}$, 由于采用 了对数放大器, 信号的动态范围达 $100 \mathrm{~dB}$. 当辐射峰 值超过噪音电平阈值时, 以 $25 \mu \mathrm{s}$ 的时间间隔(窗口) 获取最大峰值信号, 同时记录它的强度和时间, 峰值 信号时间的分辨率为 $50 \mathrm{~ns}$ ( $20 \mathrm{MHz}$ A/D 转换器), 每 个站的 $40 \mathrm{MHz}$ 高精度时钟和 GPS 接收机的 1PPS 脉 冲上升沿同步并被校准, 经二分频输出的 $20 \mathrm{MHz}$ 基 准信号作为 $\mathrm{A} / \mathrm{D}$ 转换器的采样时钟. 利用 7 个子站同 步确定的峰值到达的绝对时间, 对其闪电辐射源进 行三维时空定位. 系统用 $25 \mu \mathrm{s}$ 窗口处理一次峰值事 件, 每秒最高能定位处理 40000 个辐射源(实际定位 辐射源数目根据各测站可识别的孤立脉冲数多少而 有所变化), 从而可以详细描绘闪电放电全过程的三 维图像.

\section{2 系统实现定位方法}

闪电击穿产生的辐射脉冲峰到达子站 $i$ 的时间 $t_{i}$ 与测站间距离有以下关系式:

$$
t_{i}=t+\frac{\sqrt{\left(x-x_{i}\right)^{2}+\left(y-y_{i}\right)^{2}+\left(z-z_{i}\right)^{2}}}{c},
$$

其中 $t$ 是辐射源在 $(x, y, z)$ 位置的时间, $\left(x_{i,} y_{i}, z_{i}\right)$ 是第 $i$ 


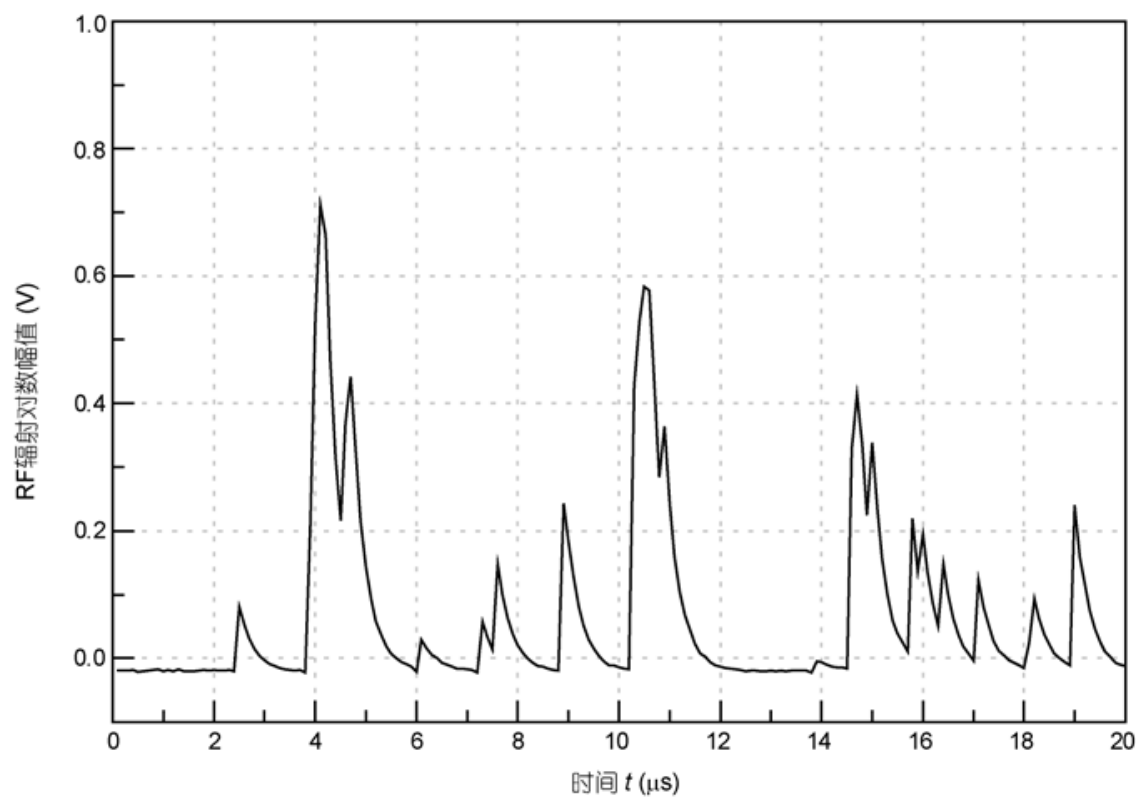

图 2 LLR 系统探测的闪电辐射脉冲波形扩展图

个测站的位置坐标, $t_{i}$ 为辐射脉冲到达第 $i$ 测站的时间, $c$ 是光速, 如图 3 所示.

利用 6 个以上测站测量的到达时间 $t_{i}$ 可以得到 6 个以上的形式如(1)式的方程, 组成非线性方程组. 求解 $x, y, z, t$ 的值应当使测量值 $t_{i}$ 和由方程 (1) 给出 的值 $t_{i}=f\left(x_{i}, y_{i}, z_{i}\right)$ 之间的偏差极小, 这里采用非线性最 小二乘拟合方法, 对该方程中参数 $(x, y, z, t)$ 予以拟合, 确定函数 $t_{\mathrm{i}}$ 的参数 $(x, y, z, t)$ 的数值, 使 $x^{2}$ 取极小值,

$$
x^{2}=\sum_{i=1}^{N} \frac{\left(t_{i}^{o b s}-t_{i}^{f i t}\right)^{2}}{\Delta t_{r m s}^{2}},
$$

$x^{2}$ 为拟合优度, 用于衡量所求的解与实际测量的到达 时间的近似程度, 通过不断的迭代求解出一组 $(x, y, z$,

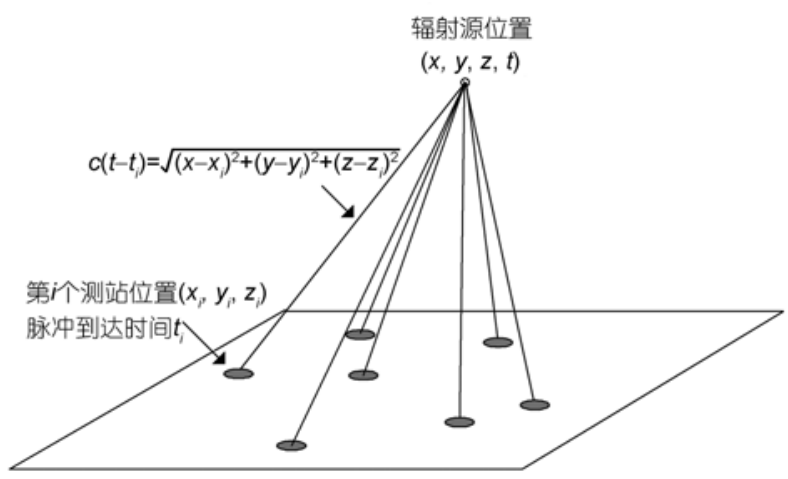

图 3 时差定位(TOA)原理图 $t$ ), 并使其最接近于测量结果，就可以得到辐射源的 三维空间位置.

\section{3 误差估计}

我们采用简单几何方法 ${ }^{[15]}$ 估计误差，假定辐射 源在两测站之间的基线上，辐射源平面距离的定位 误差相当于到达时间差值标准偏差的一半所对应的 距离误差, 高度误差同辐射源与测站间的距离有关, 当辐射源位于测站正上方时高度误差最小, 高度误 差随辐射源远离测站而增大, 可分为网内和网外来 估算本系统的误差，网内及网络附近有

$$
\Delta d \approx \frac{1}{\sqrt{2}} c \Delta t, \quad \Delta z \approx c \Delta t\left(\frac{d+r}{z}\right),
$$

其中 $\Delta d$ 是平面误差, $\Delta t$ 是每个测站的时间均方根误 差, $d$ 是最近测站到辐射源正下方的平面距离, $r$ 是最 近测站到辐射源的距离, $z$ 是辐射源相对网络平面的 高度, $\Delta z$ 是高度误差.

由于系统采用高精度 GPS 的 1PPS 脉冲同步 40 $\mathrm{MHz}$ 时钟, 存在同步误差, 即 GPS 的 1PPS 定时误差 (精度小于 $12 \mathrm{~ns}, 6 \sigma$ 平均), 单个测站总合均方根误差 约为 $18 \mathrm{~ns}$. $\mathrm{A} / \mathrm{D}$ 采样周期为 $50 \mathrm{~ns}$, 因为 $\mathrm{A} / \mathrm{D}$ 在转换 过程中存在量化误差 ${ }^{[16]}$, 所以有 $50 / \sqrt{12} \approx 14.1 \mathrm{~ns}$ 的 均方根误差, 再加上触发等误差等, 估计系统最大时 间误差约为 $50 \mathrm{~ns}$, 用公式(3)计算得出, 网内及网络 
附近(公式适用于距测站网络以外 $10 \mathrm{~km}$ 左右的范围 内), 在闪电通常发生高度 4 15 km 范围内, 水平误 差不超过 $11 \mathrm{~m}$, 高度误差一般是水平误差的 2 3 倍. 随着辐射源高度的降低, 高度误差会有细微的增大. 同时网外有

$$
\Delta r=\left\{\begin{array}{ll}
8\left(\frac{r}{D}\right) \Delta y, & \Delta y=\left(\frac{r}{D}\right) c \Delta T, \\
8\left(\frac{z}{D}\right) \Delta z, & \Delta z=\left(\frac{r^{2}}{D z}\right) c \Delta T,
\end{array} \quad \Delta T \approx \sqrt{2} \Delta t .\right.
$$

这里 $r$ 是中心测站到辐射源的距离, $D$ 是网络模型的 直径, $z$ 是辐射源相对网络平面的高度, $\Delta T$ 是两个测 站之间的接收时间误差, $\Delta t$ 是每个测站的时间均方根 误差. 计算表明, 在约 $100 \mathrm{~km}$ 范围内水平误差典型 值为 $100 \mathrm{~m}$, 垂直误差在 $300 \mathrm{~m}$ 以下, 随着距离增加 误差增大.

根据实验室内系统同步接收脉冲信号标定测试, 采用分辨率 $25 \mathrm{~ns}$ 时钟计数, 按统计结果来看, 到达 时间误差一般也在 $50 \mathrm{~ns}$. 按照光速传播速度, 辐射 脉冲信号到达各接收天线的误差一般在 $50 \mathrm{~m}$ 以下(平 面). 进一步的野外时空标定实验及详尽的误差分析 将另文撰述.

\section{3 资料分析}

\section{1 负极性地闪}

图 4(A)是 2007 年 7 月 9 日 23: 55: 40 时刻(北京 时)一次负地闪放电过程的三维时空结构, 图中绿色 正方形是测站位置, 辐射源的颜色从蓝色到紫色逐 步变化指示闪电辐射源随时间演变过程. 此次地闪 发生在距探测网络中心东南约 $30 \mathrm{~km}$ 处, 由图 4(B) 快电场变化波形显示, 这次负地闪只有一次回击, 持 续时间约 $250 \mathrm{~ms}$. 分析图 4(A) 可见, 闪电在云内 4.5 $\mathrm{km}$ 高度处开始激发, 电场呈现正向变化并伴随大幅 度的正极性脉冲发生, 表明初始激发是向下发展负 极性击穿过程, 闪电辐射源先在起始区以倾斜方向 向下向周围传播, 辐射点比较密集, 当击穿过程发展 到 $3.5 \mathrm{~km}$ 高度以下, 辐射源开始快速垂直向下发展, 引发了梯级先导过程, 先导接地点时间为 23:55:40.5269 (与山东地闪定位系统(DF)的记录结果 一致). 图 4 中还可以看到梯级先导向地面行进期间, 同时在闪电初始激发区还有新的辐射源不断发生,
回击发生后在通道的顶端和始发区周围引发了新的 闪电通道向远处发展. 以辐射源快速垂直向下传输 为负先导的开始点, 本次负地闪先导前的预击穿过 程持续时间约 $19 \mathrm{~ms}(3.5 \mathrm{~km}$ 高度以上), 梯级先导过 程持续时间约 $26 \mathrm{~ms}$ (3.5 km 高度以下), 预击穿过程 发展速度约为 $5.2 \times 10^{4} \mathrm{~m} / \mathrm{s}$, 梯级先导过程发展速度 约为 $1.3 \times 10^{5} \mathrm{~m} / \mathrm{s}$, 与 Shao 等 ${ }^{[1 \sim 3]}$ 观测结果基本一致. 这次负地闪的预击穿过程主要以负极性击穿为主, 这个阶段的电场变化波形也以正极性脉冲居多，但 也可以看到一些负极性的脉冲发生, 由此表明在以 负极性击穿为主的预击穿过程中, 也可能同时存在 正击穿过程.

\section{2 正极性地闪}

图 5(A)是一次正极性地闪放电过程的三维时空 结构图, 它只有一次回击, 发生在 2007 年 7 月 11 日 11 时 01 分 49 秒(北京时), 根据地面电场记录, 可以 确定该雷暴为三极性电荷结构. 由东西立面图和平 面投影看出, 闪电起始于 $4 \mathrm{~km}$ 高度负电荷区域, 先 朝南偏西方向发展, $10 \mathrm{~ms}$ 后向上发展到 $6 \mathrm{~km}$ 高度, 深入到正电荷区域, 产生大量负击穿过程, 又经过 $11 \mathrm{~ms}$ 后辐射源降低到 $4 \mathrm{~km}$ 高度, 并停止传输. 结合 图 5(B)可见, 此时段电场为负向变化, 且波形上叠加 了密集的正负极性脉冲, 说明在传输路径上产生大 量雪崩的负电荷并向正电荷区域内传输, 消耗区域 内正电荷量, 相反, 由雪崩过程产生的正电荷向初始 击穿点传输, 在传输过程中产生大量正、负脉冲(图 $5(B))$. 此后, 在 $4.4 \mathrm{~km}$ 高度上, 又发生大量负击穿过 程, 向水平方向延伸约 $16 \mathrm{~km}$. 上述大量的云内负击 穿过程，在消耗区域内正电荷量的同时，在初始激发 点积聚了大量正电荷, 大大地提高了该点的正电位, 最后触发向下的正地闪过程. 根据这次正地闪电场 变化波形的回击发生时间和正先导位置, 接地点发 生的绝对时间为 11:01:49.453896, 与山东地区地闪 定位网(DF)测量的一致. 回击发生后在回击点的上 方初始击穿区引发了新的闪电通道, 并向上相反的 西北方向水平发展, 传输距离约 $35 \mathrm{~km}$. 这次正地闪 持续时间约 $600 \mathrm{~ms}$, 闪电通道以开始区为中心向对 称方向发展. 回击前主要在 $4.4 \mathrm{~km}$ 的高度上传输, 平 均速度约为 $1.6 \times 10^{5} \mathrm{~m} / \mathrm{s}$, 辐射源比较集中. 回击后在 $7.2 \mathrm{~km}$ 的高度上传输, 平均速度为 $1.4 \times 10^{5} \mathrm{~m} / \mathrm{s}$, 辐射 点比较弥散, 从初始触发点向下的正先导过程, 由于 


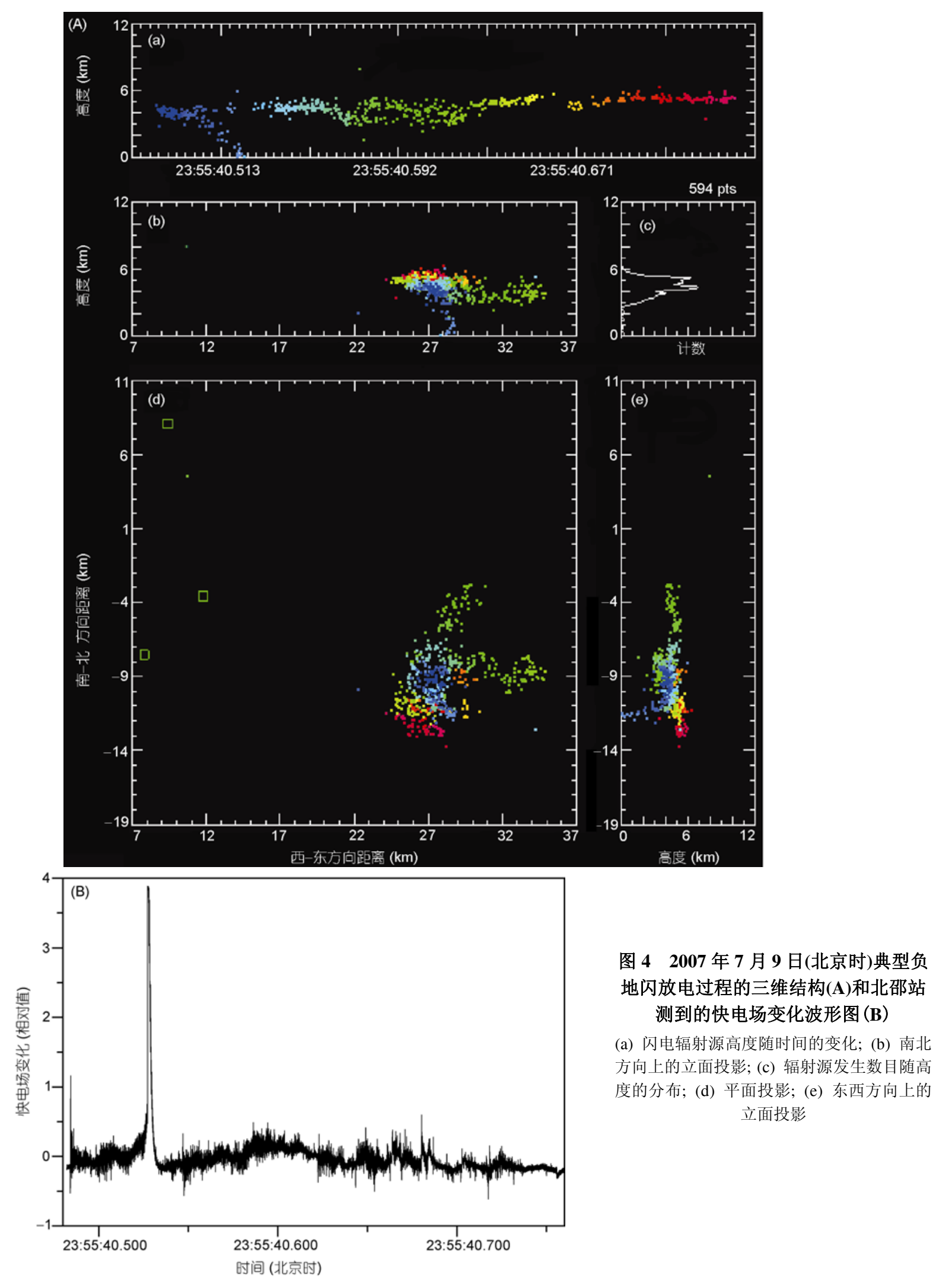



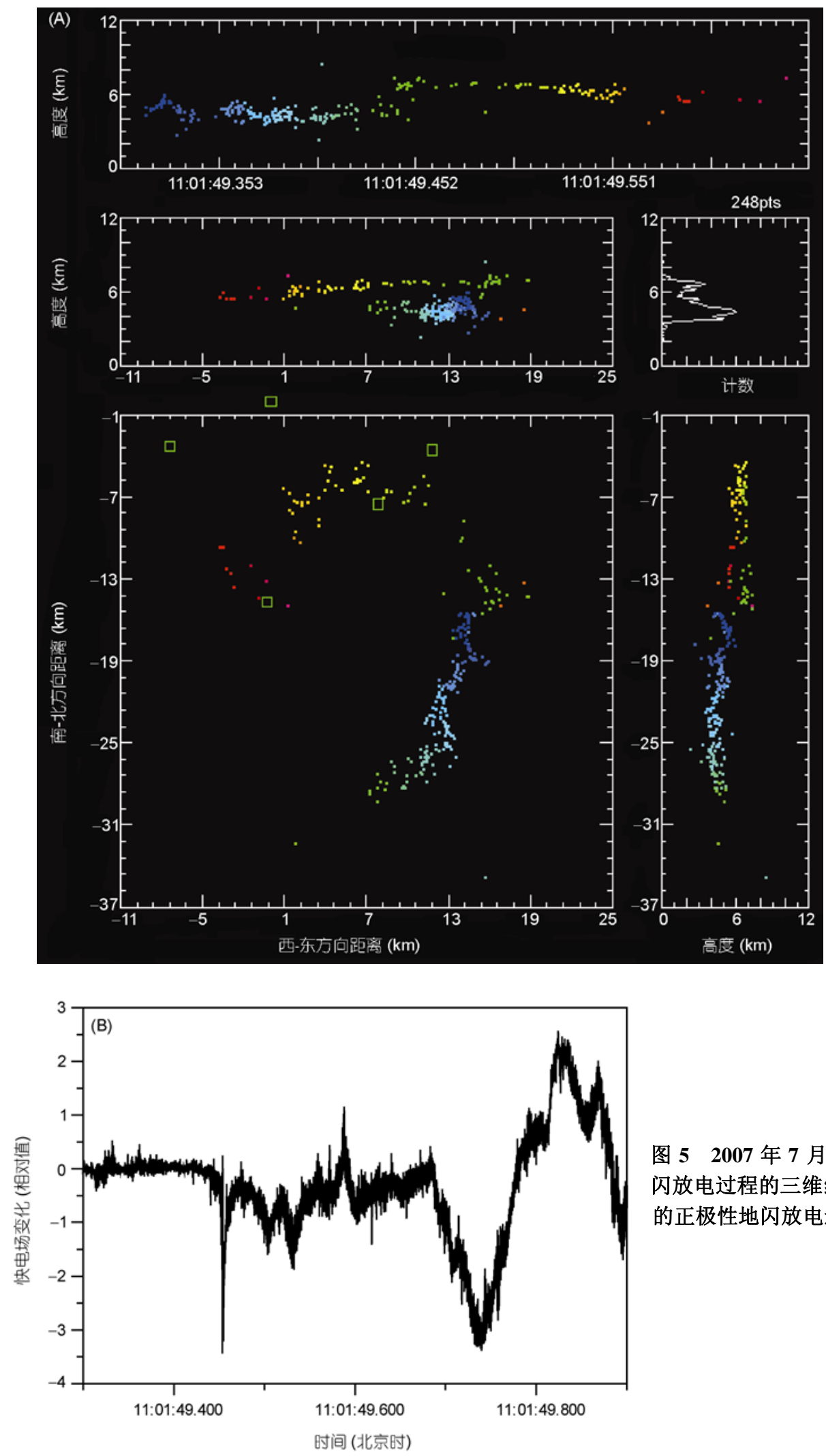

图 52007 年 7 月 11 日(北京时)正极性地 闪放电过程的三维结构图(A)和滨海站测到 的正极性地闪放电过程的快电场波形图(B) 
其辐射较弱, 未能被探测到, 与张义军等 ${ }^{[11]}$ 的结果基 本一致. 综合分析得知这次正地闪电荷区由低到高 倾斜分布，呈现出不均匀形态特征.

从上分析可见，正、负地闪的触发过程是不同的; 负地闪是在负电场环境下空气被击穿产生负流光传 输, 离开负电荷区域向下以梯级先导形式传输, 没有 或很少云内放电过程. 正地闪是在正电场环境下空 气被击穿, 由于正电荷迁移太小, 主要也是负流光传 输, 但其方向是进入正电荷区, 产生大量的云内放电 过程, 中和云内正电荷, 同时在始发点积累正电荷提 高正电位, 直到足以产生向下正流光传输. 因此, 云 内放电是产生正地闪的重要条件, 它为始发点提供 能量, 产生正地闪.

\section{3 云闪}

图 6(A)是两次云内闪电, 均表现出了双层结构, 它们发生在大约 2007 年 8 月 1 日 2 时 7 分 48 秒(北 京时), 图中的上、中、下 3 层分别对应雷暴云中部的 主负电荷区 $(8 \sim 9 \mathrm{~km}$ 高度)上部的正电荷区(11 13 km 高度)和下部次正电荷区(3 6 km 高度), 图 6(B) 是横 店站测到的云内放电的快电场变化波形图. 初始击 穿开始在 $8.7 \mathrm{~km}$ 高度负电荷区, 闪电负流光(由电场 变化确定)垂直向上进入上部正电荷区, 转向朝西南 方向水平传输, 闪电通道停止传输后紧接着在负电 荷区有少量辐射点发生, 并引发了第二次向上传输 过程, 从开始区 $7.9 \mathrm{~km}$ 高度垂直向上进入上部正电 荷区 $11.5 \mathrm{~km}$ 高度开辟了新的水平通道, 转向朝相反 的东北方向水平传输, 用约 $205 \mathrm{~ms}$ 时间结束了主负 电荷区与上部正电荷的放电过程, 从投影图可见辐 射点比较离散. 第二次云闪始发于 $185 \mathrm{~ms}$ 后, 发生 在主负电荷区与下部正电荷区之间, 这次云闪的负 流光从 $6.5 \mathrm{~km}$ 高度的负电荷区向下部正电荷区传输, 与下部正电荷区形成新的垂直连接通道, 并发生了 多次向下传输过程, 有的是沿先前形成的水平通道 传输, 从投影图看到辐射源以上下垂直连接通道为 中心向四周发展, 辐射点比较弥散.一个云闪由中部 主负电荷区负流光向上部正电荷区传输, 传输速度 约为 $1.8 \times 10^{5} \mathrm{~m} / \mathrm{s}$, 另一个云闪由中部负流光向下部 正电荷区传输, 传输速度约为 $2.9 \times 10^{5} \mathrm{~m} / \mathrm{s}$. 在这两次 云闪中一共有 1083 个辐射源, 如图 6(A)中的(c)图所 示, 下部正电荷区辐射点密集, 上部正电荷区次之, 主负电荷区最少. 从上分析可见, 云闪始发点都发生
在负电荷区域中, 开始以垂直方向向上(或向下)传输, 在逐渐接近上部(或下部)正电荷区时, 受正电荷区的 正电荷分布影响, 使负流光倾斜, 在进入正电荷区后, 与正电荷的碰撞中和, 将会产生更多的击穿过程且 会形成水平通道. 辐射点的密集度和电荷的密集度 相对应. 上述结果说明, 下部正电荷区的电荷浓度高 于上部正电荷区. 此外, 从二次云闪传输过程来看, 云中电荷宏观结构是明显分层的. 根据云闪传输的 经典概念, 可以判断这次雷暴是典型的三极性电荷 分层结构 ${ }^{[10]}$.

\section{4 双极性窄脉冲}

双极性窄脉冲(NBP) 是一种云内放电过程中伴 随产生的具有强烈的高频辐射脉冲, 近代观测发现, NBP 会孤立出现, 也会出现在放电初期, 其辐射强度 比常规闪电高一个量级. 根据经典概念, 云闪始发于 负电荷区或接近负电荷区域. 然后沿倾斜垂直方向 传输. 在进入正电荷区域之后才出现水平通道. 近代 一些观测还发现, 有些云内放电过程初始触发点在 正电荷区, 开始就有很长的水平通道, 而无明显的垂 直通道. 此外, 经典云闪在始发阶段通常是幅度较小 的脉冲, 而这类云闪在始发阶段出现的首发脉冲就 是辐度很大的双极性窄脉冲 NBP, 同时伴有很强的 $\mathrm{RF}$ 辐射, 然后才出现水平通道传输. 似乎云闪是被 双极性窄脉冲所触发, 很多学者注意研究它的机制 尚无明确结论 ${ }^{[5]}$. 本节从一次 NBP 观测个例予以讨 论.

图 7(A)是一次新型云闪过程三维时空结构图. 发生在 2007 年 8 月 1 日 2 时 11 分 02.712716 秒时刻 (北京时), 这次云闪在触发初期出现很强的双极性窄 脉冲并伴有强烈的 RF 辐射(中心频率 $270 \mathrm{MHz}, 3 \mathrm{~dB}$ 带宽 $6 \mathrm{MHz}$ ). 图 7(B)所示, 其辐射功率比常规闪电 高一个量级以上, 图 7(A)中红色叉号是该脉冲出现 的时空位置, 图 7(C) 是这次云闪的快电场变化波形. 从图可见, 初始阶段有很强的双极性窄脉冲(峰值已 进入放大器非线性区), 其起始脉冲是负极性, 峰值 大于随后的正脉冲峰值(图 7(D) 是扩展波形). 在产生 双极性脉冲同时, 产生相当强烈的 RF 辐射(图 7(E) 是扩展波形). RF 辐射通常来源于新通道的空气击穿, 而不是原通道. 图 7(F) 是 2007 年 8 月 1 日 2 时 12 分 (北京时)雷暴过程的雷达回波图(11 km 高度 CAPPI 扫描), 图 7(G)是出现 NBP(红色叉符号)的回波区剖 

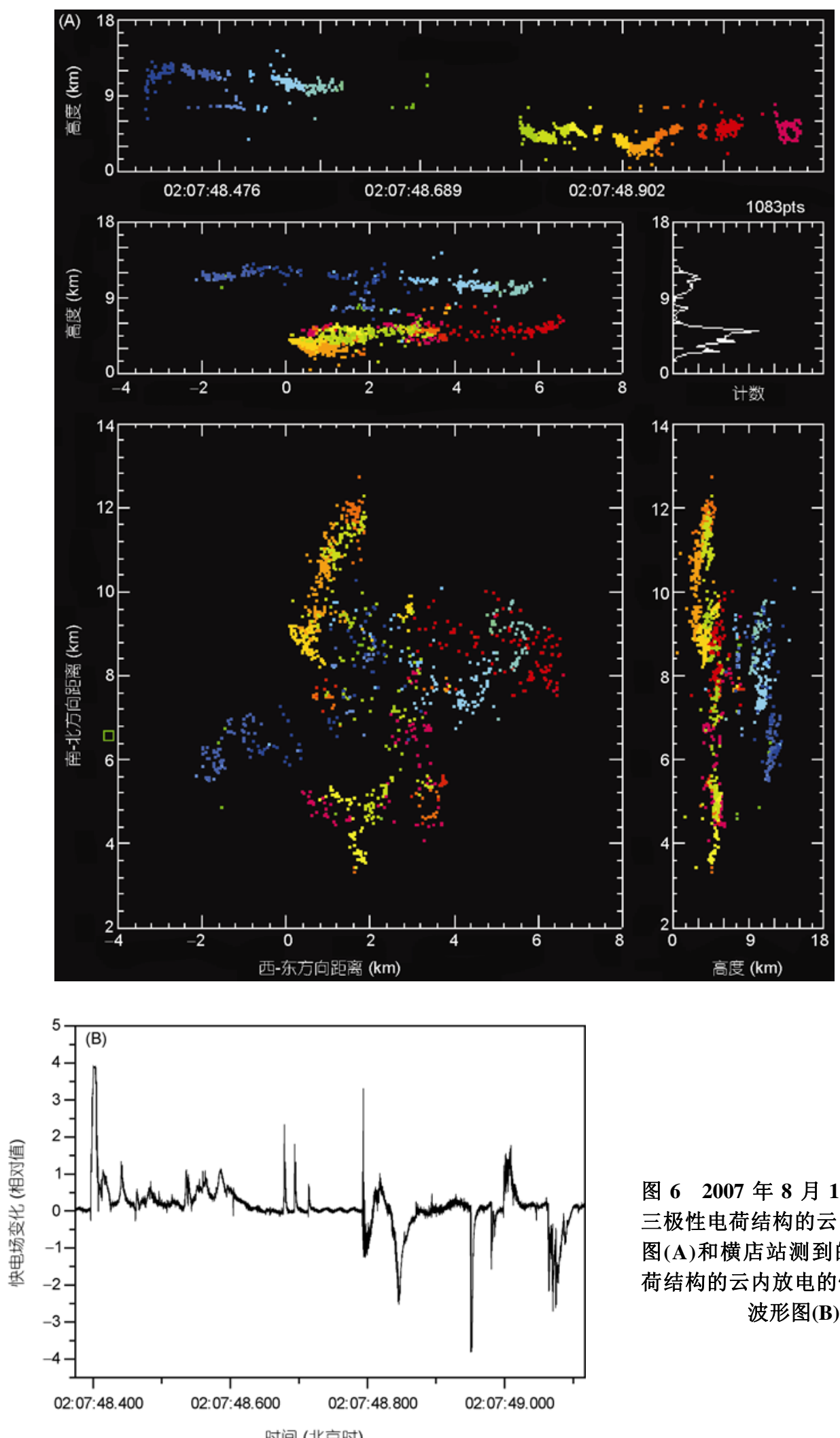

图 62007 年 8 月 1 日(北京时) 三极性电荷结构的云内放电结构 图(A)和横店站测到的三极性电 荷结构的云内放电的快电场变化 波形图(B) 

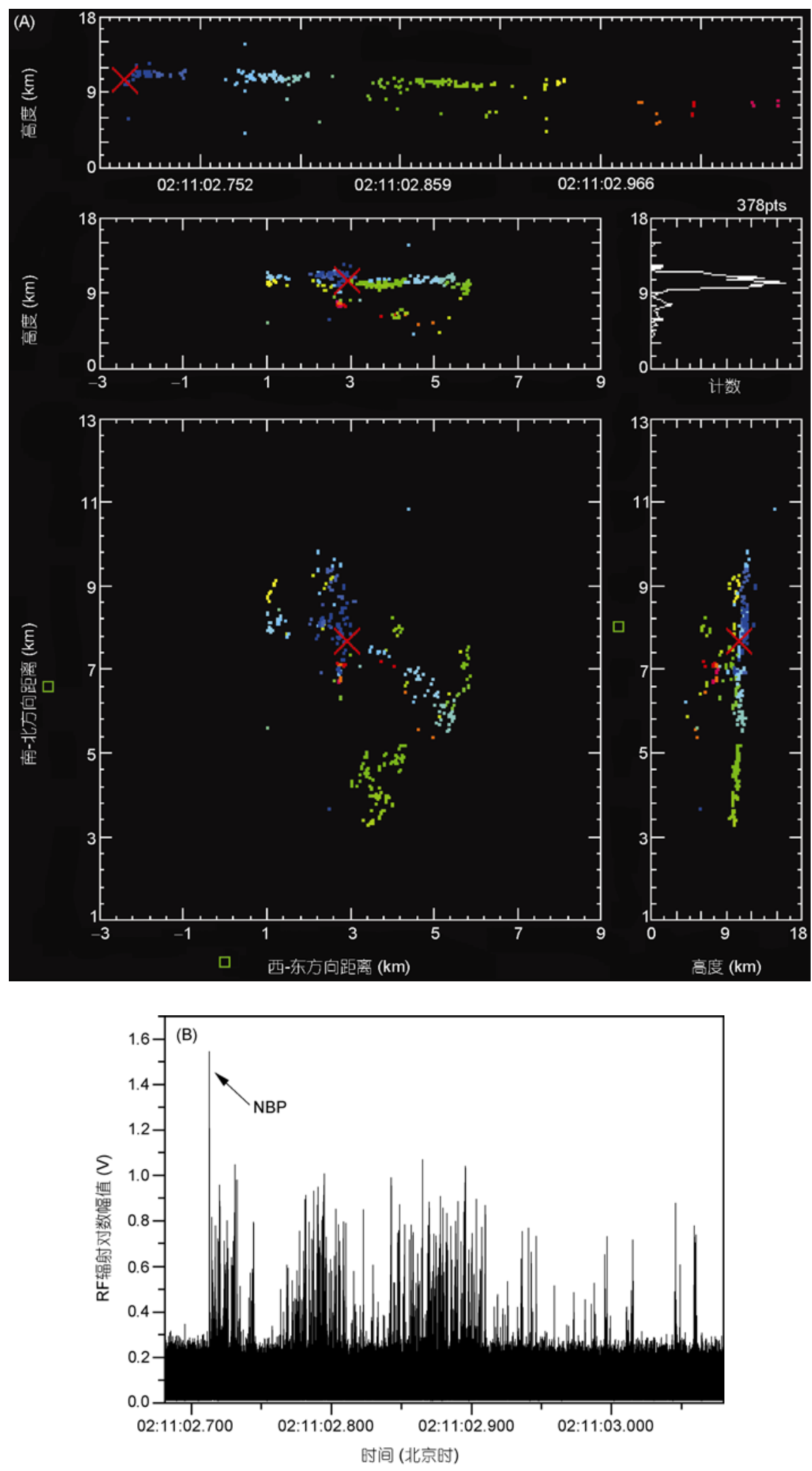

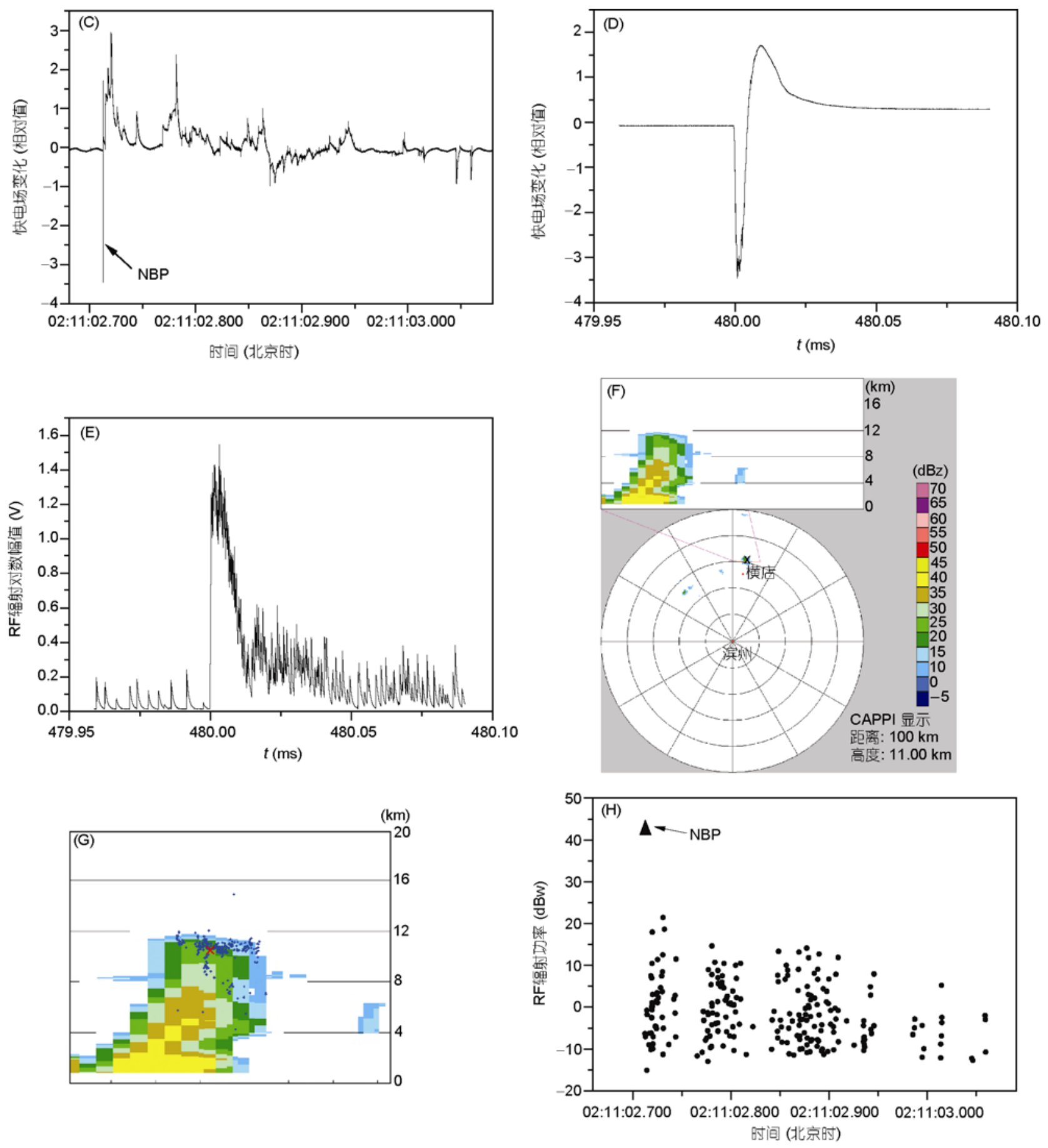

图 7

2007 年 8 月 1 日 02 时 11 分 02 秒(北京时)一次双极性窄脉冲(NBP)事件引发的云内闪电放电三维时空分布(A)、横店站测到的双极性窄脉冲 $(\mathrm{NBP})$ 事件引发云闪的 $\mathrm{RF}$ 辐射波形图(B)和快电场变化波形 $(\mathrm{C})$ 、横店站测到的双极性窄脉冲(NBP) 的快电场变化扩展波形(D)和 $\mathrm{RF}$ 辐射扩展 波形(E)、2007 年 8 月 1 日 02 时 12 分(北京时)雷暴过程的雷达回波图 $11 \mathrm{~km}$ 高度 CAPPI 扫描(F)及(F)指示的回波剖面(RHI)与闪电辐射源叠 加的扩展图 $(\mathrm{G})$ 和横店站测到的双极性窄脉冲(NBP)引发闪电的辐射源功率分布图 $(\mathrm{H})$ 
面(RHI 扫描)和闪电辐射源的叠加扩展图, 从图 7(F) 可见, 该 NBP 出现于离中心站(横店)约 $8.2 \mathrm{~km}$ 距离, 高度约 $10.5 \mathrm{~km}$ 上, 回波强度 15 25 dBz(图中叉符 号), 结合图 7(G) 可见, 在 9 12 km 范围有大量辐射 源点(图中蓝色圆点)尤其在 NBP 附近, 不同回波区域 都有发生, 但 NBP 是出现在回波强度 15 25 dBz 回波 区域中。

对于经典云闪，一般是在云闪的活跃时期才可 能出现幅度大的双极性脉冲, 近代观测发现, 云闪触 发初期也会出现一些双极性脉冲, 但其幅度一般较 小. 也就是说, 幅度很大的双极性窄脉冲可能是云闪 发展的一种结果, 而不是云闪触发的原因. 但本次云 闪个例似乎是“原因”, 问题是双极性窄脉冲如何产 生?

从图 7(A)可见, 该脉冲发生在约 $10.5 \mathrm{~km}$ 的高度 附近, 处于云内正电荷区域中, 然后沿水平方向向四 周发展, 由内向外呈 $\mathrm{X}$ 形状, 形成很长的水平放电通 道. 从图 7(A)可见, 产生非常密集的水平击穿过程. 在垂直方向上也有少量向下辐射点, 是垂直方向的 击穿过程. 上述触发传输过程, 说明该次云闪过程初 始触发是发生在正电荷区域中, 是被初始为负极性 的双极性窄脉冲触发, 且立即进入活跃阶段, 没有一 般云闪的初始预击穿过程, 其传输过程以水平通道 为主, 无明显的垂直通道. 也就是说, 云闪通道是在 正电荷区域中传输, 其触发过程和正地闪的初始云 内过程有点相似. 近代观测发现, 正地闪的触发点也 能发生在云上部正电荷区内(例如日本冬季雷暴), 初 始局地高电位触发正击穿, 负流光传输, 同时使触发 点正电位提高, 产生正击穿, 若触发点高正电位还不 能产生正击穿, 则云内负流光逐渐消失. 但是, 如果 在某些正电荷特别密集区, 开始就产生了相当高的 正电位, 已能产生正击穿并直接导致正流光传输, 且 在传输过程中遇到“局部负电荷密集区”, 正负电荷 发生强烈中和, 产生很强的双极性窄脉冲, 由于大量 正流光的正电荷被中和, 原来的负流光被加强, 产生 图 7(A)中非常密集的辐射源, 类似于一般云闪传输 过程. 因此, 我们认为, 这种云闪似是被双极性窄脉 冲所触发, 它源于正电荷区中局部极高电位区.

由于来自宇宙空间的高能宇宙射线对大气的电 离作用, 会在大气中产生不同极性的电荷堆, 尤其是 自由电子堆, 且较多出现于大气上层 ${ }^{[17]}$. 我们认为, 上述上层正电荷区域中的“反极性电荷密集区”正是
这些自由电子堆积而成. 由于大量自由电子游离于 空气中, 使这些区域的空气击穿电场阈值被大大地 降低, 可以低一个量级以上, 自由电子被电场加速, 易形成电子雪崩过程和正流光传输过程, 且在正流 光传输途中遇到 “自由电子堆”, 产生强烈中和形成 NBP. 因此 NBP 产生于“反极性电荷密集区”密切相 关, 且该区域的回波强度也不大, 这和图 7(F) 的结论 一致, 深入研究需要大量 NBP 观测资料分析, 并作 “逃逸击穿”的理论计算.

根据闪电脉冲辐射功率估算算法 ${ }^{[7,18]}$, 我们对此 次闪电进行了脉冲辐射功率的估算, 如图 7(H)所示, 双极性窄脉冲 (三角形符号) 辐射强度远大于其他 VHF 辐射源, 整个闪电脉冲辐射功率在 $100 \mathrm{~mW} \mathrm{500}$ $\mathrm{W}$ 功率范围, 而接收的双极性窄脉冲辐射功率值则 高达 $16.7 \mathrm{~kW}$, 要高出一个量级以上, 是典型的 NBP 脉冲. 此值比 Thomas 等 ${ }^{[18]}$ 的计算结果相对偏小, 可 能是因为我们采用的接收频率(中心频率 $270 \mathrm{MHz} 3$ $\mathrm{dB}$ 带宽 $6 \mathrm{MHz})$ 与他们采用的频率 $(63 \mathrm{MHz})$ 不同有关.

\section{4 结论}

本文介绍了作者自行研制的闪电三维定位测量 系统(LLR) 以及得到的观测资料, 同时结合闪电电场 变化观测资料, 分析了负地闪、正地闪、云闪以及双 极性窄脉冲引发的新型云闪过程三维时空结构, 得 到以下结论:

(1) 负地闪初始激发对应向下发展负极性击穿 过程, 开始时闪电辐射源在起始区向周围传播, 辐射 点比较密集以梯级先导形式离开云区向下传输, 根 据本次地闪放电通道三维时空结构图像对预击穿和 首次梯级先导过程做了简单划分, 得到预击穿过程 发展速度约为 $5.2 \times 10^{4} \mathrm{~m} / \mathrm{s}$, 梯级先导过程发展速度 约为 $1.3 \times 10^{5} \mathrm{~m} / \mathrm{s}$, 先导发展速度明显高于预击穿过 程.

(2) 正地闪初始激发也是负流光传输. 但方向是 在正电荷区域内, 有较长水平通道, 在负流光传输过 程中, 同时为初始激发点积累正电荷, 提高该点正电 位, 直至激发向下正先导传输, 与负地闪有所不同.

(3) 云闪大部分始发于负电荷区, 以垂直取向上 或向下传输, 进入正电荷区后呈现较长的水平通道. 雷暴电荷结构明显分层多为三极性结构, 中部的主 负电荷区 $(8 \sim 9 \mathrm{~km}$ 高度)上部的正电荷区(11 13 km 高 
度)和下部正电荷区(3 6 $\mathrm{km}$ 高度).

（4）少数云闪始发于上部正电荷区被双极性窄 脉冲(NBP)激发, 在正电荷区域内以优势水平方向传 输, 不进入负电荷区域. 此类云闪及其三维传输过程 在国内被首次发现，其产生机理有待深入研究.

(5) 对闪电活动中闪电辐射源进行了功率计算, 得到闪电辐射源功率一般在 $100 \mathrm{~mW} 500 \mathrm{~W}$ 范围内, 双极性窄脉冲辐射强度高达 $16.7 \mathrm{~kW}$, 远高于其他辐 射脉冲(用中心频率 $270 \mathrm{MHz}, 3 \mathrm{~dB}$ 带宽 $6 \mathrm{MHz}$ ).
(6) 新研制的闪电 VHF 辐射源三维定位系统, 可以高时间分辨率和空间分辨率对云闪及地闪进行 三维时空定位, 为深入研究云内放电通道机理及双 极性窄脉冲提供了非常有效的观测手段.

闪电 VHF 辐射源三维定位系统是基于时差定位 原理的高精度定位系统，对于连续辐射脉冲定位尚 有不足，作者认为通过缩小基线距离增加测站空间 密度可在一定程度上改善此问题，此类工作还有待 于今后进一步详细研究.

致谢＼cjkstart感谢 2007 年参加山东雷电观测实验的全体人员和山东省气象局; 滨州市气象局在野外实验中给予支持, 审 稿人提出建设性意见, 一并致谢.

\section{参考文献}

1 Shao X M, Krehbiel P R, Thomas R J, et al. Radio interferometric observations of cloud-to-ground lightning phenomena in Florida. J Geophys Res, 1995, 100(D2): 2749-2783

2 董万胜, 刘欣生, 张义军, 等. 利用闪电宽带干涉仪系统对地闪先导-回击过程的观测研究. 中国科学 D 辑: 地球科学, 2002, 32: 81一 88

3 张广庶, 赵玉祥, 郄秀书, 等. 利用无线电窄带干涉仪定位系统对地闪全过程的观测与研究. 中国科学 D 辑: 地球科学, 2008, 38: $1167-1180$

4 Boccippio D J, Heckman S, Goodman S J. A diagnostic analysis of the Kennedy Space Center LDAR network 1. Data characteristics. J Geophys Res, 2001, 106(D5): 4769-4786

5 Rison W, Thomas R J, Krehbiel P R, et al. A gps-based three-dimensional lightning mapping system: Initial observations in central new mexico. Geophys Res Lett, 1999, 26: 3573-3576

6 Krehbiel P R, Thomas R J, Rison W, et al. Lightning mapping observations in central Oklahoma. EOS, 2000, 81: 21-25

7 Hamlin T D. The New Mexico Tech lightning mapping array. Doctoral Dissertation. Socorro: New Mexico Institute of Mining and Technology, 2004. 31-32

8 张义军, Krehbiel P R, 刘欣生. 雷暴中的反极性放电和电荷结构. 科学通报, 2002, 47: 1192-1195

9 张义军, 孟青, Krehbiel P R, 等. 超级单体雷暴中闪电 VHF 辐射源的时空分布特征. 科学通报, 2004, 49: 499-505

10 张义军, 孟青, 吕伟涛, 等. 两次超级单体雷暴的电荷结构及其地闪特征. 科学通报, 2005, 50: 2663-2675

11 张义军, 孟青, Krehbiel P R, 等. 正地闪发展的时空结构特征与闪电双向先导. 中国科学 D 辑: 地球科学, 2006, 36: 98一108

12 祝宝友, 陶善昌, 谭涌波. 伴随超强VHF辐射的闪电双极性窄脉冲初步观测. 气象学报, 2007, 665: 124一130

13 Shao X M, Stanley M, Regan A, et al. Total lightning observations with the new and improved Los Alamos Sferic Array (LASA). J Atmos Ocean Technol, 2006, 23: 1273-1288

14 郄秀书, 余华, 张广庶, 等. 中川地区一次负地闪的起始过程研究. 高原气象, 1998, 17: 34-43

15 Thomas R J, Krehbiel P R, Rison W, et al. Accuracy of the lightning mapping array. J Geophys Res, 2004, 109(D14207): 1-34

16 马明建, 周长城. 数据采集与处理技术. 西安: 西安交通大学出版社, 1998. 21-27

17 Gurevich A V, Medvedev Yu V, Zybin K P. New type discharge generated in thunderclouds by joint action of runaway breakdown and extensive atmospheric shower. Phys Lett A, 2004, 329: 348-361

18 Thomas R J, Krehbiel P R, Rison W, et al. Observations of VHF source power radiated by lightning. Geophys Res Lett, 2001, 28: 143-146 